\title{
A Study on Constructing the Business Models of Community Development Social Enterprises from the Perspective of Social Design Strategies
}

\author{
Chang-Chih Wei ${ }^{1}$, Shang-Yun Yen ${ }^{2}$ \\ ${ }^{1}$ Ph.D. Program of Business, Feng Chia University, Business Bldg. 709 No. 100 Wenhwa Rd., Seatwen, \\ Taichung, Taiwan 40724, R.O.C. \\ ${ }^{2}$ Professor, Feng Chia University, Business Bldg. 709 No. 100 Wenhwa Rd., Seatwen, Taichung, Taiwan 40724, \\ R.O.C. \\ Correspondence: Chang-Chih Wei, Ph.D. Program of Business, Feng Chia University, Business Bldg. 709 No. \\ 100 Wenhwa Rd., Seatwen, Taichung, Taiwan 40724, R.O.C.
}

Received: May 28, 2018

doi:10.5539/ibr.v11n7p152
Accepted: June 23, 2018

Online Published: June 26, 2018

URL: https://doi.org/10.5539/ibr.v11n7p152

\begin{abstract}
With the development of globalization, countries encourage non-profit organizations or general enterprises to use the business model beyond profit, pay attention to social value and solve social or environmental problems synchronously. Social design is to solve social problems, promote innovation in the field of social reform, and solve all kinds of problems derived from social development. However, many social enterprises show enthusiasm for the society but ignore the importance of the management, which will be difficult to reach the goal of sustainable development.

This paper serves as a reference for social enterprises to build a sustainable management model from the aspects of social design, systems thinking and value proposition of business model through a case study. The enterprises can not only achieve a sustainable development by relying on government subsidies or the implementation of government plans, but also solve social problems by improving the social environment.
\end{abstract}

Keywords: social enterprises, business models, social design strategies, systems thinking, community development

\section{Introduction}

There are many local culture towns in Taiwan that are rich in natural resources and traditional techniques. Once a fascinating moment and created an early economic prosperity, but with the decline of the economic structure of the industry and the relocation of the population, the town is gradually forgotten.

According to the years of experience in coaching business district and local industries, we can see that a number of micro enterprises, small and medium enterprises lose competitiveness in the face of the social environment changes, and non-profit organizations tend to face lots of difficulties in operation management. Social enterprises are engaged in solving the social problems and enterprise management synchronously, attaching the most importance to social responsibility. The idea of social enterprise is originated in Europe and America, aiming at limiting the expenditure of government's social welfare, weakening the government's role in the field of social welfare and reducing the regulation of private enterprise, so that entrepreneurs can freely exert the profitability. This kind of social business promoted from the top down, usually indicating the industrialization of NPO and government guidance, as well as the social entrepreneurship in the rich countries.

The object of this study is the social enterprises that aim to promote regional development. These enterprises mostly depend on cultural and creative industries, commodity sales, travel as the source of income, however, some doubts remain on whether they can achieve the development of regional economy and change the social environment in the course of operation. This paper explores the sustainable purpose of the cultural and creative enterprise by analyzing the business model in light of social design pattern. 


\section{Literature Review}

\subsection{Social Design}

In a book titled Design for the Real World, the design reviewer Victor Papanek pointed out that designers should change their starting point of thinking from "objects" to "life" and "people" (Papanek, 1972). As Nigel Whiteley said in the book named Design For Society, most designers will traditionally create attractive products to encourage consumption, however, they should reflect on the negative influence and impact of the design when creating profits for the capitalists (Whiteley, 1997).

In a narrow sense, social design aims to promote social welfare, and now to solve social problems through the application. An Indian social enterprise wants to solve the problem of drinking water, and improves the system of water treatment in the process of social design without the systems thinking on lifestyle, indicating that water treatment is not the only way to solve the problem of drinking water if conducting a further discussion. In 2012, Social design's implications for the IS Field presented a guidance for the identification of commercial design and social design, referring to Table 1 (Dell, D. A., \& Venkatesh, M., 2012).

Table 1. Social Design and Commercial Design

\begin{tabular}{ll}
\hline Social Design Project & Commercial Design Project \\
\hline Creating value for the public & Creating value for self-interest \\
Developed by volunteers from the community & Expanded by members of the organization \\
Managed by community members & Managed by leaders of the organization \\
No external control or governance structure & Organizational governance structure \\
Vulnerable to social dilemmas & Less social dilemma \\
Quantifiable performance & Quantitative performance measurement \\
\hline
\end{tabular}

\subsection{Systems Thinking}

System dynamics has been widely applied in various fields after Forrester's proposal, including engineering, economics, and management (Forrester, 1961; Xiao Zhitong, Weng Yuhong et al., 2010). "Systematic thinking is a practice of 'seeing the whole'." Its essence lies in transforming our spiritual thinking, "observe the interaction of circular causality instead of linear causality," and "observe a series of changes instead of fragmentary single event." The practice of system thinking can begin by understanding the simple concept of giving back. To give back can be illustrated as how individual action multiplied or offset. In system thinking, each influence is both cause and effect. Nothing is affected only by one direction (Peter and St. Kitty, 2015; Guo Jinlong, 1994). (Wei Naijie, Liao Vio et al., 2015)

Systematic thinking is the study based on System Dynamic, which is a circular thinking mode outside linear thinking. It was first mentioned by scholar Checklandy in his 1981 book on Soft Operation Research (SOR) (Forrester, 1994). The enterprise is a typical complex system. The components of a complex system are nonlinearly related, thus anti-intuitive feature appears frequently, that is, feeling isn't reality. Therefore, system theory is one of efficient methods when studying complex systems. So system theory is one of the effective methods for studying complex systems (Luo Shihui, Fan Jinyuan et al., 2014).

Systems thinking is systemic thinking instead of systematic thinking, and Senge contributes to the systematization of systems thinking. Systems thinking is a kind of thinking mode extended from system dynamics. As Senge has mentioned in "the fifth discipline", many sophisticated tools for prediction and analysis of enterprise management often make few positive contributions. Systems thinking is a visual (graphic) language, used to describe various cyclic interaction and morphological changes. Its final purpose is to help us figure out the simple structure of the events behind the complex operation, which makes the human society less complex. The system has four characteristics: (1) existing in the environment; (2) made up of some subsystems; (3) having interrelatedness among each subsystem of the system; (4) having its main function or target (Tsai Tun-Hao, 2010)

Feedback is a core concept of systems thinking. Causal Loop Diagrams (CLD) shows the causal relationship of variables in the diagram with arrows (e.g. $\mathrm{A} \rightarrow \mathrm{B}$ ), $\mathrm{A}$ for the independent variable (reason) and $\mathrm{B}$ for the dependent variable (result), and the diagram $\mathrm{A} \rightarrow \mathrm{B} \rightarrow \mathrm{C} \rightarrow \mathrm{A}$ is a so-called CLD. In addition to the type of CLD, the feedback can be divided into two categories: one is the change in the same direction, marked by "+", the so-called positive feedback loop, forming a self-reinforcing loop; the other is the reverse change, marked by "-", the so-called negative feedback loop, forming a self - regulatory loop. 


\subsection{Business Models}

Business model is also known as management model, enterprise model, operation model, or commerce model. Along with the trend of globalization and networking in business world, business model changes more rapidly. How to establish an ideal business structure and adjust the innovation of business model dynamically has become an important subject day by day.

As to the research on the operation model, Johnson et al. (2008) has proposed that business model is composed of four interlinked elements together to create value. The first element is the customer value proposition: the success of a company lies in the ways to create value for customers and help customers complete the work well. Then the formula of profit: the company creates profits for customers and itself at the same time. The third element is the key resources, such as personnel, technology, equipment and pathway needed in the process of production, generally referring to the key factors of creating value for the customer and the enterprise. The last element is key process: in the operation and management process, each corporation will repeatedly perform various routine tasks, such as training, planning, manufacturing, sales and service, to create profits and enhance its scale. Holloway and Sebastiao (2010) refers to the concept of Johnson et al. (2008) that in the process of creating profits, the enterprise's new business model mainly comes from the continuous experiment and correction of linking elements.

Hamel (2001) proposed that the business model must include four major elements: the core strategy and strategic resources; the customer interface and the value network. These four elements interact with each other and generate three types of connections: configuration, customer benefits, and company boundaries. Luo Shihui, Fan Jinyuan et al., 2014). Osterwalder, Pigneur and Tucci (2005) believe that the business model is also to link business strategy, business organization and information system as a triangle core point, and at the same time assess the competitiveness of the external environment, regulatory environment, social environment, consumer demand and technological changes. Tools for achieving business strategy (Chen Longhui and Huang Ziming, 2017).

Peter Drucker pointed out that the competition among enterprises today is not the competition between products, but the competition of business models. In addition, in the era of rapid technological development, how to integrate the speed from the product side to the consumer side and create service value together It is also an important key factor. The business model is mainly to explain the principles of enterprise creation, transmission and value acquisition (Osterwalder \& Pigneur, 2010), which consists of four elements: customer value proposition, profit formula, key resources, and key processes (Johnson, 2008) (Luo Shihui, 2014, 2016). Osterwalder and Pigneur (2013) divided all corporate business models into nine elements, describing how to establish and evaluate business models. The business model is used to explain how companies can deliver customer value at an appropriate cost to gain profits (Magretta, 2002). The four elements of the business model can be further extended to the business model of Osterwalder and Pigneur (2009), including 1. Customer Segments, 2. Value Propositions, 3. Channels, 4. Customer Relationships. (Customer Relationships), 5. Revenue Streams, 6. Key Resources, 7. Key Activities, 8. Key Partners, 9. Cost Structure.

\subsection{Social Enterprises}

Martin and Osberg (2007) emphasize it is obliged to give a clear boundary before making a definition of social enterprise, because too broad definition will be meaningless, and generally speaking, people often confuse social enterprises with non-profit organizations. In fact, the mode of enterprise management is established to solve the situations non-profit organizations are faced with, such as a highly competitive environment of donors and grants, the increasing social demand and a general tightening of funds, forcing them to take a more powerful attitude in their business activities, to pay attention to the achievements of government policy, to provide exceptional value for the target market in an innovative way, and to become competitive social organizations. So Weerawardena and Mort (2006) point out that social enterprises should strive to integrate resources and exert the ability of sustainable development in order to create social value in the spirit of innovation.

The difference between social enterprises and general enterprises lies in the different motives, general enterprises are driven by money, and social enterprises are driven by altruism instead of money. The main mission is to create social value, while to create economic value is a necessary but not sufficient condition (Mair \& Martí, 2006). The target of transferring enterprise value is to solve the short of resources, being ignored, or extremely vulnerable population, and they lack financial means or political influence to change the status quo (Martin \& Osberg, 2007). The difference of the mode of transferring value between traditional enterprises and non-profit organizations lies in, social enterprises aims at enabling the target group to bear their own destiny through learning and employment, etc., being involved in value activities, and promoting personal and social 
development (Mair \& Schoen, 2005).

European and American social enterprises do not have the names of "community-based" social enterprises or "community development social enterprise." However, due to the guidance of public policies in Taiwan, the research on the role of community non-profit organization commercialization or social enterprise in the community development process has been well-researched (Lin Yijun, 2008; Pelchat, 2005; , 2007; Kuan and Wang, 2010b; Qiu Changtai, Zhou Jinhong, 2007; Qiu Lianzhi, Guan Youyi, 2010; Lin Jiaxuan, 2011; Zhang Wenling, 2005). Recent studies also discovered that community-based social enterprises have become an important feature of Taiwanese social enterprise development (Chan et al., 2011; Defourny and Kim, 2011).

In September 2014, the "Social Enterprise Action Plan" is approved in Taiwan by 12 ministries and councils that beneficial to enterprise innovation, entrepreneurship, and ecological environment development. It provided friendly environment for social enterprise development, also constructed the network and platform for social enterprise. With the goal of strengthening the management of social enterprises, execute laws, build platform, raise funds, and promote education, are 4 major strategies, various types of social enterprises will be originated by ministries and councils. In order to encourage the development of social enterprises, the Executive Yuan adopts both the broad and narrow definition of operational types. Among them, general incentive measures are used to broaden the needs of various parties, adopt a broad operational definition, and refer to international relevant data to develop narrowly defined operational definitions in order to encourage social enterprises move toward the development of information transparency, furthermore, to guide TWSE and OTC listed companies to comply with CSR funds into such social enterprises to assist them in their development.

Definition of generalized operation: Organizations that solve specific social or environmental problems through business models, whose surplus is mainly used for their own reinvestment, in order to solve the social or environmental problems on a continuous basis, rather than only seeking the maximum benefit from the investor or the owner. In terms of organizational characteristics, social enterprises pursue social and economic interests at the same time, but the main mission is to create social influence. In terms of organizational form, it can be in the form of a general profit-making business or a non-profit organization. Its type of concern is quite diverse, including weak care, local development, ecological environmental protection, and fair trade.

\section{Research Method}

This paper will conduct an exploration through the case study which refers to the specific and in-depth study of a single objective, namely "Townway" in this study. The research framework is mainly based on the business model, with the theory of enterprise business model and materials, divided into four directions, namely: value proposition, profit formulas, key resources, key processes (Johnson and et al., 2008), as shown in Figure 1; furthermore, drawing the dynamic loop diagram of enterprise management to explore the possible limits and side effects of growth, and then to find out the place where the bottleneck may occur; finally, developing strategies to identify the leverage and business model for the maximum benefits.

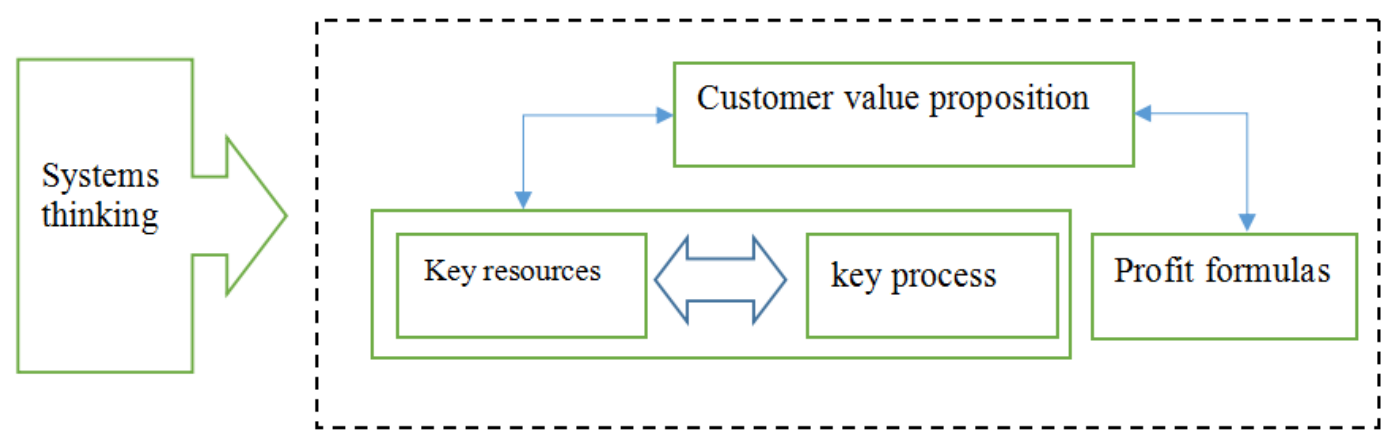

Figure 1. Research Framework

\section{Research Results}

The company started from the Bed \& Breakfast called "sky yard", repairing the hundred years of construction, and committed to the integration of culture and industry, to create more products combined the old culture with new ideas. Facing the field of few tourism resources, Mr. He Pei-Chun puts forward the concept of "let tourists become sociologists", in the approach of "work exchange" and "expertise feedback", attracting many external resources to assist the development of Zhushan township; by the mode of "cooperation in design, production and sales" to help local businesses implement innovative activities, stimulate the economy and create new value. After interviewing the person in charge, residents and young entrepreneurs of Zhushan Township, the business 
models are sorted out as follow, according to the theory of enterprise business model and collected materials (Johnson et al., 2008).

Table 2. Business Model of Townway Enterprises

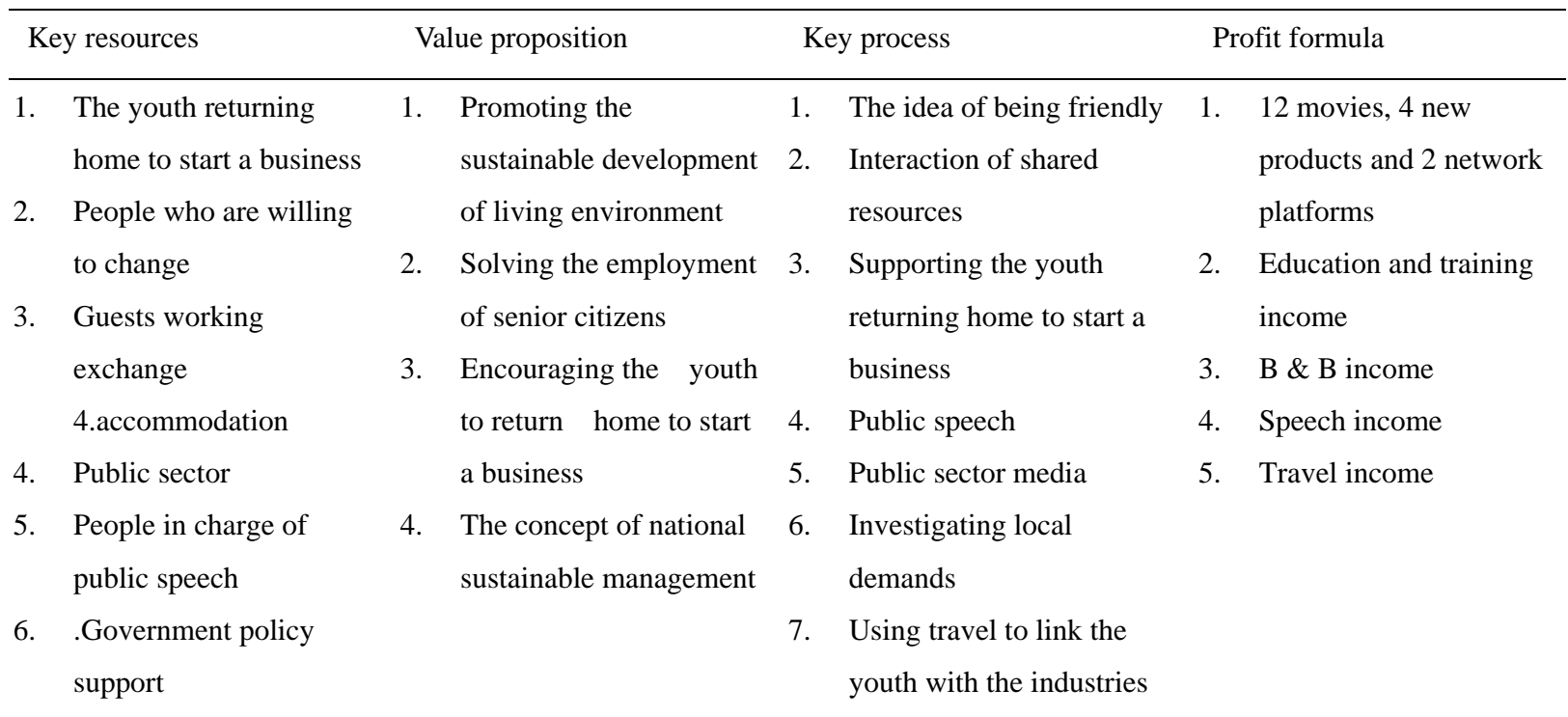

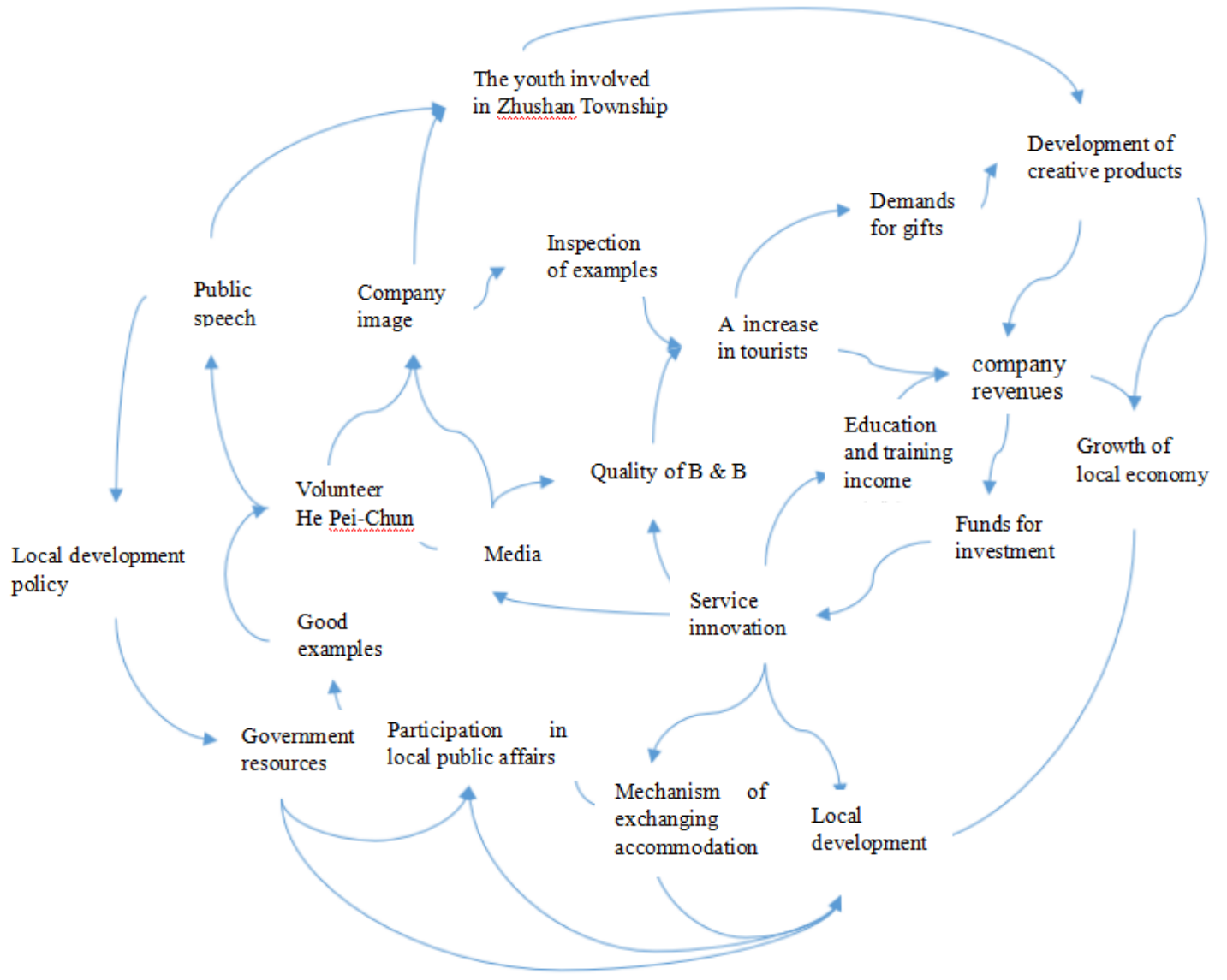

Figure 2. The Dynamic Structure of Creative Business Model 


\section{Conclusions and Research Limitations}

\subsection{Conclusions}

Social entrepreneurs seem to be innocent and romantic, but also pragmatic, because they can deconstruct the collective anxiety under modernity, escape from extremely pure rationality and create the operating mode of sustainable management and profitability. This paper takes the Townway social enterprise as a research object, to explore the business model by using the systems thinking, and finds that its business model is in line with the current trends of knowledge economy.

In this case study, the advantages of business model lies in service innovation and volunteers, forming a reciprocal causation: service innovation increases small experiential activities like travel, which becomes the subject of education and training, and then increases the revenue and volunteers' exposure to enhance the overall image of the company. Operating income creates more profits, and the company can develop more service innovation, forming a benign loop. Therefore, the town invests more resources and creates new service mode to link the youth entrepreneurship and the senior entrepreneurship, promoting the development of local economy, becoming a virtuous cycle to enhance volunteers' image, to attract and encourage more young people to take part in.

\subsection{Academic Implications}

Based on the systems thinking, this paper explores the business model of the Townway company, while researches in the past focus on the conceptual discussion of business models (Holloway and Sebastiao, 2010; Johnson et al., 2008; Johnson and Suskewicz, 2009), or a further instructions for a specific industry or case (Bekmezci, 2013; Gutiérrez, 2010), however, lacking the exploration of the interaction among the various elements of business models. This research constructs the successful business model of the Townway company through systems thinking. As the regional development of social industries gradually attaches more importance to service innovation, this paper explores the interaction and connectivity among the various elements of service innovation from the perspective of systems thinking, which are employed in the business model proposed by Johnson et al. (2008).

\subsection{Research Limitations}

In light of the deficiencies of this paper, the suggestions for future research and development are as follows: information should be rich in a further integration of literature and materials, to establish the theoretical basis and driving source of general business model with systems thinking and knowledge economy, to promote the interaction of theory and practice in the fields of academia and industry. According to analytic results and feedback diagram, the systems modeling and analysis should be conducted through a qualitative research on the basis of system dynamics, to explore the interaction (feedback) among the components, and the results of data analysis will lead to more direct and convincing findings.

\section{References}

Cai, D. H. (2010). Management, Taichung: Bohai Publishing.

Chen, L. H., \& Huang, Z. M. (2017). "A Study on the Business Model of Social Enterprise in Kobayashi Taking [2021 Social Enterprise] as an Example." Fu Jen Management Review, 24(1), 47-75.

Defourny, J., \& Kim, S. Y. (2011). Emerging Models of Social Enterprise in Eastern Asia. Social Enterprise Journal, 7(1), 8 -111. https://doi.org/10.1108/17508611111130176

Evers, A., \& Laville, J. L. (2004). "Defining the third sector in Europe." The third sector in Europe 11. https://doi.org/10.4337/9781843769774.00006

Forrester, J. W. (1994). "System dynamics, systems thinking, and soft OR." System dynamics review, 10(2-3), 245-256. https://doi.org/10.1002/sdr.4260100211

Hamel, G. (2001). Leading the Revolution. Boston. MA: Harvard Business School Press.

Ho, M. F., \& Lin, B. (2015). "Export logic: The evolution of business models in emerging markets." Zhong Shan Management Review, 23(1), 91-135.

Holloway, S. S., \& Sebastiao, H. J. (2010). The Role of Business Model Innovation in the Emergence of Markets: A Missing Dimension of Entrepreneurial Strategy? Journal of Strategic Innovation and Sustainability, 6(4), 86-101.

Johnson, M. W., Christensen, C. M., \& Kagermann, H. (2008). Reinventing Your Business Model. Harvard Business Review, 86(12), 50-59. 
Luo Shihui, et al. (2014). "Discussing the Management Model of Taiwan's Grand Teams from a Systematic Perspective." International Journal, 6(4), 225-240.

Luom S, H., \& Huang, S. H. (2016). "Study on innovative business model of aesthetic medicine in dermatology clinics." Journal of Medical Management, 17(2), 150-167

Mair, J., \& Marti, I. (2006). "Social Entrepreneurship Research: A Source of Explanation, Prediction, and Delight". Journal of World Business, 41, 36-44. https://doi.org/10.1016/j.jwb.2005.09.002

Mair, J., \& Schoen, O. (2005). "Social Entrepreneurial Business Model: An Exploratory Study". Working Paper No. 610, IESE Business School.

Martin, R. L., \& Osberg, S. (2007). "Social Entrepreneurship: The Case for Definition". Stanford Social Innovation Review, 2(5), 28-39.

Osterwalder, A., \& Y. Pigneur (2010). Business model generation: a handbook for visionaries, game changers, and challengers, John Wiley \& Sons.

Osterwalder, A., et al. (2005). "Clarifying business models: Origins, present, and future of the concept." Communications of the association for Information Systems, 16(1), 1.

Papanek, V. (1972). "Design for the real world: making to measure 1972."

Papanek, V., \& Fuller, R. B. (1972). Design for the real world (p. 22). London: Thames and Hudson.

Senge, P. M. (2006). The Fifth Discipline: The Art and Practice of the Learning Organization, London: Century.

Senge, P. M., Kleiner, A., Roberts, C., Ross, R., \& Smith, B. (1994). The Fifth Discipline Field Book: Strategies and Tools for Building a Learning Organization, New York, NY: Doubleday.

Wang Yi, et al. (2015). "The Big Issue and Social Enterprise Relationships." Journal of Graphic Arts and Communication, 315-324.

Weerawardena, J., \& Mort, G. S. (2006). "Investigating social entrepreneurship: A multidimensional model". Journal of World Business, 41, 21-35. https://doi.org/10.1016/j.jwb.2005.09.001

Wei, A., \& Nai, J., et al. (2015). "Discussion on Application of Systems Thinking Methods in Business Strategies." Journal of Commercial Modern Chemistry, 8(1), 37-44.

Wright, D., \& Donella, H. (2012). Meadows. Thinking in systems. Taylor and Francis, 2012.

Yang, C. Z., et al. (2016). Systematic thinking on the analysis of evacuation and asylum in flood-prevention and disaster-prevention communities and research on countermeasures". Taiwan Water Resources, 24(6), 55-61

Yang, M. X. et al. (2009). "The construction of social enterprise business model." Research on Entrepreneurial Management, 2009, 12.

\section{Copyrights}

Copyright for this article is retained by the author(s), with first publication rights granted to the journal.

This is an open-access article distributed under the terms and conditions of the Creative Commons Attribution license (http://creativecommons.org/licenses/by/4.0/). 